\title{
Language and Translation as Weapons of Effective Communication and Success in Ministry
}

\author{
Olugbuyi Adejoke Olumayowa \\ Department of General Studies, Federal Polytechnic, Ado Ekiti, Nigeria
}

\begin{abstract}
Communication is the life wire of any community, family and organisation. Language is a powerful weapon of communication and success in ministry. At various levels of human endeavour - at home, in the office, in the church there is need to use language. Success in life is attributed to effective and appropriate use and interpretation of language. This paper aims at considering the use of language and translation in achieving effectiveness in communication and success in ministry. This is done in order to ascertain the importance of language and translation to the growth and expansion of the church or organisation. To do this, through the use of questionnaires some organisations and churches that use more than one language will be examined vis-a-vis those that employ only one language for ministration. Also some recorded messages will be considered in order to identify some of the problems encountered by interpreters during translation of messages. Tentative solution will be provided to the problem so identified. This paper will also highlight some of the factors that can help both speakers and interpreters use and interpret language appropriately. There is need for adequate knowledge of the vocabulary of the language, correct pronunciation, use of appropriate stress and intonation in order to achieve effectiveness in communication and success in ministry.
\end{abstract}

\section{Introduction}

What is communication? The term communication has been given various definitions but one can say that communication is passing of understandable information from one person or group of persons to another person or group of persons. Communication is vital to human existence. All human beings engage in communication and it is through communication that interaction is made possible amongst individuals in a society. When we talk of communication we refer to all the various means by which human beings can make their feelings known to one another in a community. This can be through the use of gestures, signs, language and so on.

The universal nature of communication has accorded it great importance to the extent that many writers have tried to give numerous definitions to it. From the various definitions given to this term the following facts have been established:

a. In communication encounter certain variables are usually present. These include the speaker, the receiver, channel, feedback and noise.

b. There must be cooperation between the participants; otherwise, communication cannot be effective.

c. There is need for all participants in communication encounter to associate the same meaning to the words used in the language, otherwise the message will not be understood.

d. Communication is passing of understandable information

e. Communication is a process and as such it involves action, interaction, and reaction. It is a see-saw exchange of role and none of the participants occupies a permanent position in communication encounter.

f. Communication is more embracing than language. Language is just a means of communication.

\section{What is the difference between communication and language?}

Language is synonymous with communication but the two terms do not mean exactly the same thing. Language is employed in communication but it is not every time we use language that we are communicating. Many times, people use language to confuse and mislead the audience through the use of wrong code, wrong pronunciation, wrong intonation, wrong accent, and wrong interpretation arising from limited knowledge of the vocabulary of the language being used. Other animals do communicate even though they do not use 
language. Language is human and all human beings except the deaf and dumb use language. Apart from language, there are other methods like gestures, postures, dressing, drumming and so many other means that human beings employ to communicate. In fact, intonation, stress and paralinguistic phenomena also contribute to meaning in communication. Therefore, communication is more than the use of words as it is employed in speech and writing.

Language is so important to human existence to the extent that no human activity or interaction is possible without language. Language is a very strong unifying factor and that was why in Genesis 11:1-9 when God diversified human language, the construction of the Tower became impossible. Thus with diversified language and increase in population, the need for the people in the world to communicate and interact increases on daily basis. Therefore, there is also need for translation to unite the various regions and peoples of the world.

\subsection{What is translation?}

There are so many definitions of translation but according to B. J. Chutte quoted by Ojeaga [1].

'Translation is a bridge between cultures... without translation ... our world would narrow miserably like air and sunlight and good growing earth in the natural world, translation is our necessity in the creative world'

Translation is employed in every aspect of human activities. For instance, in religious, scientific, cultural and social activities there is need for people to understand one another. There is need for comprehension across cultures and languages. Thus Abdul says 'translation is the bridge between languages and cultures... in a world of cultural, economic, social and technological changes [2]. Today, in many conferences and religious organisations, interpreters are employed to translate or interpret messages so as to ensure understanding and comprehension.

If language is so important, how then can we ensure effectiveness in communication through the use of language and translation? What approach should we adopt in translating or interpreting messages? What are the guidelines available for interpreters so as to convey meaningful information to their audience?

In order to answer the above questions this paper will consider some written and translated expressions in Yoruba and English languages with the aim of highlighting some of the factors that can affect interpretation and change of meaning in communication. In addition, attempt will be made to identify and discuss some of the problems involved in translating or interpreting messages. This will be done, with a view to suggesting how to overcome the problems so identified in order to achieve effectiveness in communication. The importance of appropriate use of words and good translation in achieving effectiveness in communication and success in life will also be highlighted.

For the purpose of this study, the word 'ministry' means the work that one is assigned to do or the office or post that one is occupying. Thus, we can have the ministry of a Pastor, a Teacher, a Housewife, a Doctor, Lawyer and so on. Language is employed in every aspect of human life. Our success and failure in whatever work we do or whatever position we occupy; is determined by our ability to use and interpret word effectively. In the family for instance, communication is the fuel that keeps the marriage going- any marriage where communication is lacking will collapse. Where there is communication, it is also necessary to use words appropriately otherwise, there will be chaos. Soft word brings cola while harsh word draws sword.

\section{Language as the genesis of creation/creative power of words}

In the beginning, God created the heaven and the earth, the earth was without form and God said: 'let there be light ... let there be firmament .... And there was light.... and there was firmament... etc' Genesis 1: 1-24. Thus with the spoken word the world and everything came into existence. The earth took shape and everything was brought forth by the power of the word. God conceived the idea but nothing happened until He spoke. Language is the foundation of creation.

We are created in the image of God, therefore, whatever idea we conceive, until we translate it into words such an idea will never see the light of day. We can shape our destiny through the spoken words. In the book of Numbers chapter 14:28 God said 'As truly as I live, says the Lord, 'as ye have spoken in mine ears, so will I do to you'. He commanded prophet Ezekiel to prophesy to dead bones and the dead bones stood up and became 'an exceeding great army Ezekiel 37:1-10.

When we bring the above discussion into the realm of academics Dr Johnson quoted by Quirk 
says that 'language is the dress of thought' [3]. This means that it is language that can crystallise and give shape to the beautiful ideas we conceive in our minds. There is creative power in the words we use. Language is not only a means of communication; rather it is a powerful weapon of ideological control. Language is a tool for survival, a passport to prestige, economic success and political power. [4]. Noah describes language as a non-instinctive method of putting across our thoughts, desires, ideas, ego and personality to the world usually through a sound meaningful correspondence.... it is unthinkable how man and the modern city state could survive without some form of language [5]. Whatever is achievable or is human is through language because language underlies our cognitive ability'

According to the definitions above, language is one of the greatest blessings that God has bestowed on man. The importance of language is seen in a situation whereby we do not understand each other simply because we speak different languages. For example, let us consider the case of deaf and dumb people or the case of a baby who cannot speak but is crying and the mother cannot understand what he wants. One can imagine how worried the mother would be. Social interaction is made possible through language.

Another thing about language is that it is only useful when it communicates effectively the mind of the speaker to the recipients. This is only possible when the participants in communication encounter share the same meaning of all the words used in the language. For communication to be effective there must be isomorphism of meaning between the participants. According to Wilbur the communicators in communication encounter must share the same field of experience and the same meaning before communication can be effective [6]. It is when there is shared meaning between the participants that we can say that communication has taken place [7].

\section{The role of translation in effective communication}

Language manifests at two levels, the verbal and non verbal. The verbal involves the use of words as in speech and writing. The non verbal as in use of gestures, signs, paralanguage, pictures, graph and so on. When we speak, gestures accompany the spoken words. Gestures convey additional meaning to the listeners in oral communication. Therefore, the speaker must use appropriate gestures during speech making otherwise, the listener will take the gesture to be the real meaning of what the speaker intends. It usually said that actions speak louder than voice. If a student goes to a lecturer's office and say: 'sir, can I discuss my problem with you?' and the Lecturer says: 'yes go on'. But the lecturer starts to look at his watch and continues to write. The student will believe that even though the lecturer's reply to his request is positive, he does not have time to listen to his problem. In oral communication both speech and action must agree in order to ensure effectiveness in meaning. When husband and wife are discussing they watch each other's facial appearance in other to ascertain the truthfulness of the message that is being passed across. Each of them will want to know whether the other party agrees or disagrees with his or her own point of view in the discussion.

Apart from gestures the effect of intonation, stress and accent is also important in communication. In Yoruba language for instance, accent and intonation plays a vital role in conveying meaning and interpreting messages. It is with the use of accent and intonation that a listener with be able to know the difference in meaning between: 'igba' - (garden egg ) and 'igba' - 'time'. Even in English some words that have the same spellings can have different meaning as a result of the use of stress. For example: REbel - (noun) and reBEL - (verb); also 'Present and pre'sent; 'Insult and In'sult. In English language, with the use of stress and intonation we can effect change of meaning. An interpreter must have good knowledge of the use of stress and intonation in order to interpret effectively otherwise, such an interpreter will end up confusing his or her audience. For example, an interpreter who erroneously interpret the biblical expression 'comfort ye my people' in Yoruba language as 'Comfoti yi enia mi ni' instead of 'tu enia mi ninu' made the mistake because of his inability to differentiate between 'Comfort - (noun) and com'fort - (verb).

Pronunciation is another important aspect to consider in communication. To communicate effectively both the speaker and the interpreter must have good knowledge of the correct pronunciation of words in the language of discourse. Words like 'sword', 'awesome', 'coup', 'corps' are sometimes mispronounced by some Nigerians users of English language. When a speaker pronounces should as /suld/ instead of 
/sud/; sword as /swod/ instead of /so:d/, it can lead to confusion. English speakers of certain ethnic origin in Nigeria find it difficult to differentiate between cheer and chair; share and cheer; sit and cheat. Sounds such as /z/, /v/ that are not present in the indigenous languages are sometimes pronounced wrongly by some Nigerian users of English. During speech making both the speaker and the interpreter must take note of the correct pronunciation and structure of the language of discourse.

Every language has its own peculiarity in terms of word formation and structure. For instance, the structure of forming words in Yoruba language is consonant followed by vowel (CVCV) or vowel followed by consonant (VCVC). This is found in Yoruba expressions such as - baba, labalaba, tabili, abebi, oba, obe, etc.. In English language it is different. The structure of English language permits cluster of consonants - for example in words such as 'across', 'success', through' - we have VCCVCC, CVCCVCC, and CCCVVCC respectively. Word formation and usage vary from one culture to another and from one language community to another language community. It is according to the world view and experiences of the users of the language that words are formed and interpreted.

The outcome of the research conducted on the churches that were examined shows the use of indigenous language interpreted into English is an advantage in churches. Those churches that use two different languages grow faster numerically than their counterparts that employ only one language to preach. There is creative power in words. Life and ministry can be transformed through effective and positive use of words. Success and failure in business is dependent on how knowledgeable and effective we are in the use of words. Success is determined by how we express our mind to the public. One needs to use the right expression to advertise one's product in order to maximize profit. No one can know your product no matter how good it is, except you advertise it. In other to be effective one needs to learn the art of speaking effectively. In addition, interpreters should also use expressions that will convey the real meaning and intention of the speaker to the audience. Conclusively, both in speaking and in interpreting messages, there is need to use appropriate gestures, intonation, stress and precise expressions. Success in business is dependent on the use of words therefore; it is always good to be exact and positive in the use of words

\section{Conclusion}

Language is a major means of communicating ideas to the public. In every area of human endeavour, there is need to use language. As a result of the importance of language, success or failure in life and ministry is determined by how knowledgeable and effective a man is in the use of his language of communication. For this reason, in business or in ministry, it is always good for a man to employ the language in which he is most competent.

As a result of diversified language and culture among the people in the world, there is need for translation-especially if we want to publicise, advertise or project our ideas to the whole world. It is through translation that this is made possible. For this reason, interpreters just like speakers must learn to use language effectively.

In conclusion, from the above discussion, it is evident that a man without language is dead because he cannot be heard, it is what is spoken that can be heard. Man is created in the likeness of God. If everything in creation came into existence through the spoken words, then with the write use of language we can create our own world and open our grave and destiny. Language is the gateway to success in life and ministry. If the above discussion is adhered to, our success in life and ministry is guaranteed.

\section{References}

[1] Ojeaga P. "The possibilities of Good Translation" Nigerian University French Teachers Association (NUFTA) Proceedings of 3rd Annual Conference held in Abia State University, Uturu. $8^{\text {th }}-11^{\text {th }}$ November 2000.

[2] Abdul, Z.A "Le Role De La Traduction dans l'Enseignement du Français Langue Étrangère dans » ' 'La Revue D'Etudes françaises D'Ilorin (REFI) Vol 1, no 1,2007 p. $49-56$

[3] Quirk R. Use of English, Richard clay (The Chaucer Press), Ltd. Great Britain. 1962.

[4] Olugbuyi A. O. "Language for National Intergraton and Unity: the Nigerian situation". Journal of Research and Education (JORIE) vol 1 no 1, College of Education Ikere,, Ekiti state. Nigeria. 2003, pp. 64-72

[5] Noah P., "From ethic marginalization to linguistic cleansing" Proceedings of the $9^{\text {th }} \mathrm{Bi}$-annual conference of Modern Languages, Associations of Nigeria (MLAN), University of Benin $10^{\text {th }}-13^{\text {th }}$ February, 1999. 
[6] Wilbur S. 'Measuring Another Dimension of Readership' Journal Quaterly. Vol. 24 , 1947 pp 293 300

[7] Olugbuyi A. O., Communication in English Made Simple. R.R.R. Press Educational Publishers, Nig. Ltd. Akure, Ondo State. Nigeria. 2001 